\title{
Model Verification for Material Parameters of Titanium Alloy Ti-6AL-4V and Steel
}

\author{
Guanfang Zhu' ${ }^{1,2, a}$, Chunwang $\mathrm{Li}^{1}$ and Zhongping Zhang ${ }^{1}$ \\ 'Institute of Science, Air Force Engineering University, Xi'an, 710051, China \\ ${ }^{2}$ Institute of photonics and photon-technology, Northwest University, Xi'an, 710069, China
}

\begin{abstract}
To carry out numerical simulation of TC4 titanium alloy blade impacted by foreign objects effectively, this paper takes the test results of steel ball and sandstone impacting titanium alloy flat blade inlet and blade surface as the benchmark, and uses ANSYS/LS-DYNA software to adopt kinematic hardening plasticity model to simulates the impact results and inverts the contact stiffness factor and the other three parameters were obtained by the way of inversion reasoning.
\end{abstract}

\section{Introduction}

The foreign object damage of the blade is of great significance for ensuring the reliability and flight safety of the aero-engine. The research methods are divided into experimental and simulation calculations. At present, there are many kinds of literature on simulation of blade impact damage [1-10]. And the material models used are also various. Different material models correspond to different material performance parameters, and kinematic hardening plasticity model proposed by Cowper-Symonds is one of the commonly used models. When this model is selected, a total of 1 calculation parameter and 9 material performance parameters are involved. On the one hand, for the same material, the material performance parameters of different materials are not only different but also far apart; on the other hand, most of the literature does not give all the material performance parameters and calculation parameters required for the full-stage simulation calculation, which reduces the reference value of the existing literature simulation results.

\section{Experimental study}

\subsection{Scheme 1 analysis}

According to the blade sample used in the steel ball impact test of the inlet vane of the flat blade in 1999 by Joseph L. Hamrick et al. ${ }^{[1]}$, the same flat blade geometry model is established here, as shown in Fig. 1. The steel ball has a diameter of $2 \mathrm{~mm}$, and the flat blade has a thickness of $1.27 \mathrm{~mm}$, a width of $4 \mathrm{~mm}$, and a height of 6 $\mathrm{mm}$.
The finite element discretization of the geometric model of the flat blade and the steel ball is performed In the ANSYS/LS-DYNA by using the SOLID164 unit. The grid element size of the flat blade is $0.05 \mathrm{~mm}$, and the size of the steel ball mesh unit is $0.1 \mathrm{~mm}$. Fixing the joints at one end of the flat blade, the steel ball impacts the intake side of the flat blade vertically at a speed of $305 \mathrm{~m} / \mathrm{s}$, and draws a dip with a depth $\mathrm{D}$ and a width W at the inlet side of the blade, as shown in Fig. 2.

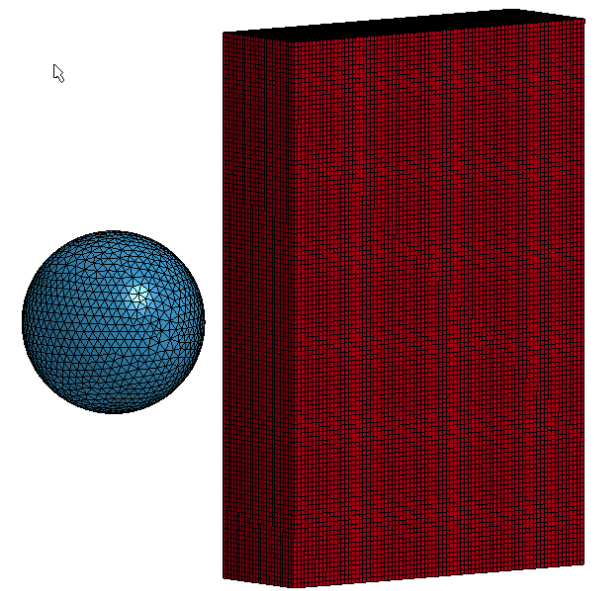

Figure 1. Steel ball impacting flat blade model

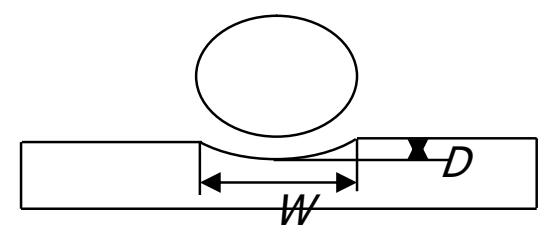

Figure 2. Geometric definition of the dent aroused by steel ball impact

\footnotetext{
a Corresponding author: author@e-mail.org
} 
The flat blade is Ti-6A1-4V material, and the kinematic hardening plasticity model is adopted; the steel ball adopts the piecewise linear constitutive model. The contact way of Erode nodes to the surface of point-toface is adopted, wherein the blade is a target body and the steel ball is a contact body. During the verification process, the hardening parameters, strain rate parameters
C, P, and contact stiffness factors were repeatedly adjusted. Finally, it was found that only when the contact stiffness factor was 0.7 and the other three parameters were listed in Table 1, the calculation results were close to the test results. The specific calculation results are shown in Table 2 and Figure 3.

Table 1. Material parameters and calculation parameters

\begin{tabular}{ccccccccc}
\hline $\mathrm{M}$ & $E\left(10^{9}\right)$ & $\sigma_{0.2}\left(10^{9}\right)$ & $v$ & $\varepsilon_{f}$ & $E_{t}\left(10^{9}\right)$ & $\beta$ & $C$ & $\mathrm{P}$ \\
\hline Alloy & 112.5 & 0.95 & 0.33 & 0.2 & 1.139 & 0.2 & 200 & 15 \\
\hline Steel ball & 200 & 1.62 & 0.3 & 0.06 & 2 & & 40 & 5 \\
\hline
\end{tabular}

Table 2. Comparison of test and simulation results

\begin{tabular}{lccccc}
\hline \multicolumn{2}{c}{ ent $D$} & \multicolumn{3}{c}{ Dent $W$} \\
\hline TSD & TSD & TSD & TSD & TSD & TSD \\
$(\%)$ & $(\%)$ & $(\%)$ & $(\%)$ & $(\%)$ & $(\%)$ \\
\hline 0.691 & 0.691 & 0.691 & 1.688 & 1.688 & 1.688 \\
0.60 & 0.60 & 0.60 & 1.90 & 1.90 & 1.90 \\
13.2 & 13.2 & 13.2 & 12.6 & 12.6 & 12.6 \\
\hline
\end{tabular}

*TSD means test simulation deviation (\%)

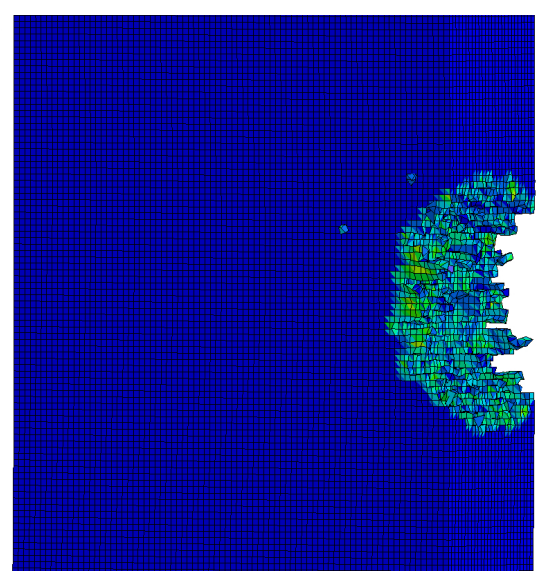

Figure 3. Damage of the flat blade after collision

\subsection{Scheme 2 analysis}

The numerical simulation of the test was carried out by using a $3.2 \mathrm{~mm}$ diameter steel ball and the TC4 titanium alloy (Ti-6A1-4V) plate was impacted in the vertical direction at impact speeds of $300 \mathrm{~m} / \mathrm{s}$ and $200 \mathrm{~m} / \mathrm{s}$, respectively. The titanium alloy plate has a thickness of 2 $\mathrm{mm}$ and a width and height of $6 \mathrm{~mm}$, as shown in Fig 4.

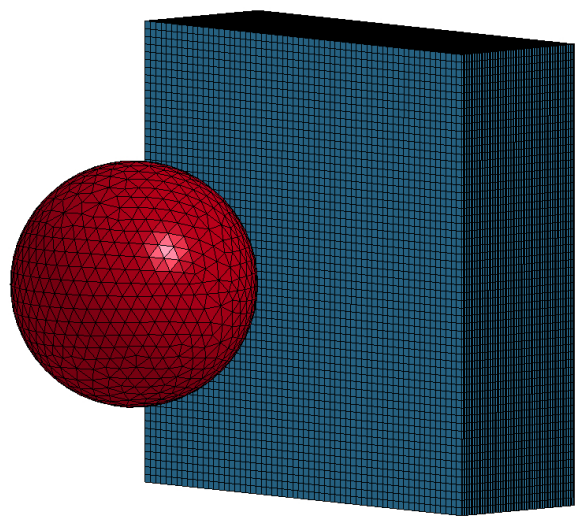

Figure 4. The model of steel ball impacting plate

The finite element discretization of the geometric model of the flat blade and the steel ball is performed In the ANSYS/LS-DYNA by using the SOLID164 unit. The grid element size of the flat blade is $0.05 \mathrm{~mm}$, and the size of the steel ball mesh unit is $0.2 \mathrm{~mm}$. The flat plate adopts a plastic follow-up hardening constitutive model; the steel ball adopts a piecewise linear constitutive model. Surface erosion contact between the steel ball and the titanium alloy plate was settled. The bottom surface of the titanium alloy plate is constrained along the normal direction. 
During the verification process, the hardening parameters, strain rate parameters $\mathrm{C}, \mathrm{P}$, and contact stiffness factors were repeatedly adjusted. Finally, it was found that only when the contact stiffness factor was 0.7 and the other three parameters were listed in Table 1, the calculation results were close to the test results. The specific calculation results are shown in Table 3.

Table 3. Comparison of test and simulation results $(\mathrm{T}=$ test, $\mathrm{S}=$ simulation, $\mathrm{D}=$ deviation)

\begin{tabular}{cccccc}
\hline \multicolumn{3}{c}{ Dent $D(300 \mathrm{~m} / \mathrm{s})$} & \multicolumn{3}{c}{ Dent $W(200 \mathrm{~m} / \mathrm{s})$} \\
\hline \multirow{3}{*}{$\mathrm{T}$} & $\mathrm{S}$ & $\begin{array}{c}\mathrm{D} \\
(\%)\end{array}$ & $\mathrm{T}$ & $\mathrm{S}$ & $\begin{array}{c}\mathrm{D} \\
(\%)\end{array}$ \\
\hline \multirow{2}{*}{0.67} & 0.67 & 0.67 & 0.43 & 0.43 & 0.43 \\
0.77 & 0.77 & 0.77 & 0.53 & 0.53 & 0.53 \\
14.9 & 14.9 & 14.9 & 23.3 & 23.3 & 23.3 \\
\hline
\end{tabular}

\section{Discussion}

The depth of the impact dent calculated in the first scheme is smaller than the experimental value, and the depth of the impact dent calculated in the second scheme is larger than the experimental value. In order to make the calculated values of the dent depth in the two schemes close to the experimental values, a compromise method was adopted in the selection of the material parameters $\mathrm{C}$, $\mathrm{P}$ and the contact stiffness factor of titanium alloy and steel. When the material parameters are as shown in Table 1, the calculated dent depth values for both solutions are close to the test values. When the material parameters are changed again, only the calculated dent depth of one of the solutions is closer to the experimental value, and the calculated value of the other scheme is far from the experimental value.

\section{Conclusion}

1. Using ANSYS/LS-DYNA software to adopt kinematic hardening plasticity model to simulates the impact results which helps to provides a viable method for testing residual stress and structural strength of materials.

2. By comparing the simulation value with the actual collision effect value, the material parameters are obtained by inversion reasoning, and the residual stress and the mechanical strength are calculated and predicted by using these parameters.

\section{References}

1. Joseph L Hamrick, II, BS, M S. Effects of foreign object damage from small hard particles on the high cycle fatigue life of Ti-6Al-4V. AFIT / DS / ENY / 99-02. 1999

2. B.L.Boyce, X.Chen, J.W.Hutchinson. The residual stress state due to a spherical hardbody impact. Mechanics of Materials. 2001, $3: 441 \sim 454$.

3. Wiggenraad J F M, Zhang $X$, Davies G A $O$. Impact damage prediction and failure analysis of heavily loaded, blade-stiffened composite wing panels[]]. Composite Structures, 1999, 45(2):81-103.

4. Martin N F. Nonlinear finite-element analysis to predict fan-blade damage due to soft-body impact[]]. Journal of Propulsion \& Power, 2015, 6(4):445-450.

5. Huang Z. Parameters and Methods for Evaluating Bird Impact Damage of Fan/Compressor Blade[J]. Aeroengine, 2005.

6. Sun $Z$, Lu Q. INVESTIGATION ON SIMULATION OF FOREIGN OBJECT IMPACT DAMAGE TO COMPRESSOR BLADE[J]. Journal of Aerospace Power, 1989.

7. Chen $X$, Jiao $R$, Kim K S. On the Ohno-Wang kinematic hardening rules for multiaxial ratcheting modeling of medium carbon steel[J]. International Journal of Plasticity, 2005, 21(1):161-184.

8. Choi Y, Han CS, Lee JK, et al. Modeling multiaxial deformation of planar anisotropic elastoplastic materials, part I: Theory[]]. International Journal of Plasticity, 2006, 22(9):1745-1764.

9. Tang J Y, Liu X, Dai J. Study on corner contact shock of gear transmission by ANSYS/LS-DYNA software[J]. Journal of Vibration \& Shock, 2007, 26(9):40-44+50.

10. Zhang F. Simulation Analysis of Gear Transmission Impact Characteristic-based on ANSYS/LS-DYNA[]]. Journal of Mechanical Transmission, 2011, 35(9):9-11. 